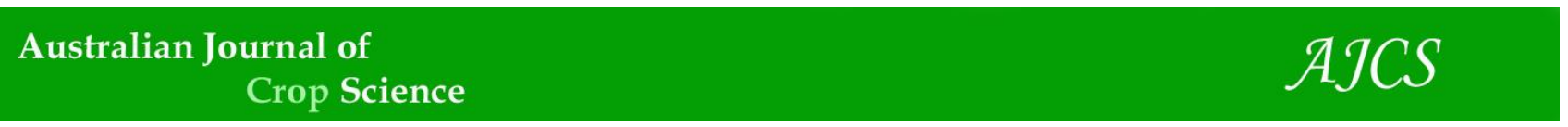

AJCS 15(05):676-682 (2021)

ISSN:1835-2707

doi: 10.21475/ajcs.21.15.05.p2996

\title{
Structural and functional stability of photosystem-II in Moringa oleifera under salt stress
}

\author{
Sadia Bashir ${ }^{1,4}$, Misbah Amir ${ }^{1 *}$, Faiza Bashir ${ }^{5}$, Muhammad Javed ${ }^{3}$, Adnan Hussain ${ }^{4}$, Saba Fatima ${ }^{1}$, Rabia \\ Parveen ${ }^{1}$, Aneela Kanwal Shahzadii ${ }^{1}$, Shehrooz Afzal ${ }^{1}$, Shumaila Raza ${ }^{1}$, Tooba Horain ${ }^{1}$, Ayesha Iqbal ${ }^{4}$, \\ Ayesha Pervaiz ${ }^{4}$, Atiq-ur-Rehman ${ }^{2}$, Ahsan Ayyaz ${ }^{1 *}$, Zafar Ullah Zafar ${ }^{1}$, and Habib-ur-Rehman Athar ${ }^{1}$
}

\author{
${ }^{1}$ Institute of Pure and Applied Biology, Bahauddin Zakariya University, Multan 60800, Pakistan \\ ${ }^{2}$ SAKIMS College for boys Bahadurpur, Multan, Pakistan \\ ${ }^{3}$ Department of Botany, University of Education, D.G. Khan Campus, Pakistan \\ ${ }^{4}$ Institute of botany, Quide e Azam campus, University of the Punjab, Lahore 54590, Pakistan \\ ${ }^{5}$ Institute of Plant Biology, Biolgical Research Center, Hungarian Academy of Sciences, Hungary 6726.
}

*Corresponding authors: misbahamir95@gmail.com, Ahsanayazmsc2015@yahoo.com

\begin{abstract}
The photosynthetic efficiency in plants is affected by salinity. Focus of this study was to observe the consequences of salinity on the rate of photosynthesis in Moringa (Moringa oleifera L.) plants. Experiment was conducted under field conditions with 3 replicates and data of treated and non-treated plants was collected accordingly. Photosynthetic rate was affected by different levels of salt stress. The change in photosynthetic was attributes were determined by OJIP and light response curve calculations by using Fluor Pen [FP 100-PS (Photon system, Czech Republic)] and DUAL-PAM-100 (Walz, Germany). Salinity stress decreased chlorophyll a fluorescence characteristic. The significant quantity of electron transport $(\phi E 0)$, quantum yield of primary photochemistry ( $\phi P o)$, proficiency per trapped excitation $\left(\Psi_{\mathrm{o}}\right)$ and performance index of photosystem II (PSII). Performance index (PI $\left.{ }_{A B S}\right)$ was also declined with salinity in $M$. oleifera. Our results showed that electron transport rate and photosynthetic rate were inhibited by salinity in $M$. oleifera. However, in $M$. oleifera electron transport pathway of PSII was repressed and found varied in plants which are salt resistant. It was concluded that $Y(I), E T R(I), Y(I I), E T R(I I)$, and $Y(N A)$ were decreased by increasing salinity while NPQ, $Y(N D), Y(N O)$ and $\mathrm{Y}(\mathrm{NPQ})$ increased in plants having resistance to salt stress.
\end{abstract}

Keywords: Salt stress, Light response curve, OJIP, PSII, Non photochemical quenching.

Abbreviations: Area-Area between Fo and Fm, Fo-Fluorescence intensity calculated when all reaction centers of PSII were opened; many other factors may effect this calculated value, Fm-Chlorophyll fluorescence intensity calculated maximum when all the reaction centers of PSII were closed, Mo-Curve slope when fluorescence rise, value of primary photochemistry rate, Vj-Relative variable fluorescence at phase J, Vi-Relative variable fluorescence at $30 \mathrm{~ms}, \mathrm{Sm}$ - (Area) (Fm - Fo), reflecting the energy required to close the all reaction centers, $\mathrm{N}$-The number which show that by reaching fluorescence to maximum value, how many times $\mathrm{QA}$ reduced, ABS/RC-Absorbance per reaction center, DI/RC-Energy dissipation per absorbance, ET/ABS-Electron transport per absorbance, TR/ABS-Trapping energy per absorbance, RC/ABS-Reaction center per absorbance, Fj-Fluorescence intensity at J-phase in induction curve ( at $2 \mathrm{~ms}$ ), Fi-Fluorescence intensity at I-phase in induction curve (at $30 \mathrm{~ms}$ ), Fv-Fluorescence variable (Fm - Fo), $\mathrm{Fv} / \mathrm{Fm}$-Value linked with maximum quantum yield of PSII, Fv/Fo-Value related to the water-splitting complex activity on donor side for stomatal conductance of PSII, PI ABS-the performance index, Y(II)-Quantum yield of PS (II), ETR(II)- Electron Transport rate (II), NPQ Non-photochemical quenching, $Y(N P Q)$-Quantum yield of non-photochemical quenching by dissipation of energy, $Y(N O)$ Quantum yield of non-photochemical fluorescence quenching by non-dissipation of energy, $Y(I)$ Quantum yield of PS (I), ETR(I) Electron Transport rate (I), Y(ND) Quantum yield of non-photochemical energy emission in reaction centers, incomplete by electrons donor deficiency, $\mathrm{Y}(\mathrm{NA})$-Quantum yield of non-photochemical energy emission in reaction centers, incomplete by deficiency of electron acceptors, qN-Nnon photochemical quenching of inconstant chlorophyll fluorescence, qP-Photochemical quenching of inconstant chlorophyll fluorescence,

Introduction

Moringa oleifera belongs to family Moringaceae native species of India and Pakistan (Leone et al. 2015). Moringa is a marvel tree and known as "Sohanjna" in local language which has multiple uses such as biogas, water sanitization, and effective for drugs and can be used directly as vegetable. It is usually cultivated almost in every type of soil at height ranging from $600-1800$ feet (Jama et al. 1989). The warm tropical areas considered to favorable for its cultivation. It is drought tolerant plant, can withstand acidic and basic soil ranging from $\mathrm{pH}$ 5.0-9.0 and to huge range of annual rainfall from $250-3000 \mathrm{~mm}$ (Jama et al. 1989). 
Plant development and efficiency is greatly influenced by the salinity. It is considered that around $7 \%$ property of the world is influenced by salinity and a minimum salinity damage of about $20 \%$ plant yield (Munns and Tester et al. 2008). Salinity decreased crop yield by affecting the photosynthetic machinery of crop plants. Salt stress adversely affects the photosynthetic pigments, which consequences in reduced enzymes activity involved in fusion of different photosynthetic pigments with reduced reaction center size and photosynthetic efficiency at PSII (Khalid et al. 2015). In that circumstance's salinity can destroy photosynthetic apparatus, plants have only way to evolve excessive amount of energy in the form of heat (Baker et al. 2008). Salinity stress reduces osmotic potential of soil and may decrease plant water potential, or it may increase ion absorption in plants, in this condition plant can delay its digestion processes (Kalaji et al. 1993).

Salinity stress causes extra storage of ions (sodium and chloride) in plant and reduces plant growth and development (Munns et al. 2008). The assembly of enzymes and large complexes is destroyed by the additional accumulation of these ions. Plants can endorse adverse effects of salinity by collecting compatible solutes like glycine betaine and proline in the chloroplast. The photosystem II (PSII) is protected by these osmoprotectants under salinity stress (Kalaji et al. 2011).

The effects of salinity on photosynthetic rate were determined since long by using gas exchange features, pigments of photosynthesis and chlorophyll a fluorescence kinetic analysis. However, few reports are available on PSII structural stability and functionality under salt stress conditions using $\mathrm{Chl}$ a fluorescence analysis. The fundamentals of the OJIP chlorophyll transients has been used when the photosynthetic model is placed at dark, or it is lighted with high pulse of light then fluorescence increases from nominal level of chlorophyll a fluorescence "O" to " $\mathrm{J}$ " phases about $2 \mathrm{~ms}$, because of the decrease in QA through photosystem II (PSII), it is showed via fluorescence increase to "I" level about 30ms, because of the satisfying the plastoquinone pool, and lastly, it increases from "I" to "P" level because of the roadblock towards the photosystem I (PSI) electron acceptor side (Kalaji et al. 2011).

JIP-test is non-critical, non-aggressive, useful, fast and reasonable method for the PSII activity analysis (Bussotti et al. 2010). The model of energy drift in thylakoid membranes provides the basis for JIP-test. The association among the activity of photosystem II (PSII), fluorescence indicators and logical terminologies can be determined by JIP-test. This method provides unassuming calculations which show the symmetry among the influx and discharge of energy fluctuation in photosystem II (PSII). JIP test also tells us about the possible destiny of the captivated energy. An evidence of the assembly and role of photosynthetic machinery (generally connected with PSII) can also be observed (Kalaji et al. 2011).

The DUAL PAM-100 is dual pulse amplitude fluorometer through which one can assess PSII and PSI efficiency, linear and cyclic electron transport and development of nonphotochemical quenching via xanthophyll cycle. Efficiency of PSI can also be determined by measuring absorbance at 870 and $830 \mathrm{~nm}$ light (Schreiber et al. 2008). In addition, it can help in measuring trans-thylakoid proton gradient and membrane potential using optional emitter-detector to calculate the additional important photosynthetic constraints.

\section{Results}

\section{Fast chlorophyll fluorescence attributes}

The electron transport of photosystem II (PSII) effected by salt stress which could be examined by fast chlorophyll a fluorescence in Moringa oleifera. The rise in chlorophyll a fluorescence induction (O-J-I-P) was noticed (Table S1, S2) in control of Moringa plants. High salt concentration has no significant variations in original fluorescence, but fluorescence decreased at $\mathrm{J}, \mathrm{I}$ and $\mathrm{P}$ steps considerably (Table S3, S4). The efficiency of PSII such as performance index; $\mathrm{Pl}_{\mathrm{ABS}}$ was reduced by increasing salt stress from 200 $\mathrm{mM}$ to $400 \mathrm{mM}$ in Moringa plants. $\mathrm{V}_{\mathrm{J}}$ and $\mathrm{V}_{\mathrm{K}}$ were equated below salinity levels ( $200 \mathrm{mM}$ and $400 \mathrm{mM} \mathrm{NaCl}$ ) to know the effects of salinity on rate of electron transport at donor side of PSII, at J-phase (2 ms), $V_{J}$ is comparative variable fluorescence and $V_{K}$ is comparative variable chlorophyll a fluorescence at $300 \mu$ s correspondingly

Salt stress increased $V_{J}$ and $V_{K}$ meaningfully. Mo, $S_{m}, N, \phi_{P o}$, $\Psi_{\mathrm{o}}, \phi E \mathrm{E}$ etc were equated below variable salinity levels to determine the salinity effects on rate of electron transport at the acceptor side of PSII. At high salinity levels $(200 \mathrm{mM}$, $400 \mathrm{mM} \mathrm{NaCl}$ ), Mo increased but Sm, N, $\Psi_{\mathrm{o}}$ and $\phi_{\mathrm{P}_{\mathrm{o}}}$ were decreased. The salinity effects were observed as that by higher salinity levels ( $400 \mathrm{mM}$ ) ABS/RC increased in Moringa oleifera as compared at low salt stress $(200 \mathrm{mM})$ and Dlo/RC increased at high salt level $(400 \mathrm{mM})$ while TRo/RC and ETo/RC decreased with increasing salinity (Table S3). Rate of reduction of PSII measured as $M_{0}, N, \Phi_{P_{0}} . \psi_{0}$ is significantly different due to salt stress while $F_{0}, S m, A B S / R C$ and ETo/RC are significant at level 0.001. Energy flux for energy dissipation per reaction center (DI/RC) and TRo/RC did not change due to salt stress (Table S4, S5).

\section{Light response curve measurements}

The valuation of light reaction kinetics is linked with PSI and PSII. As stated (Kramer et al. 2004). A competition found between these parameters as an increase in effectiveness cause decrease in the amount of other two parameters. However, evidence obtained by the alternation in the photochemistry effectiveness and energy discharge by calculating the amount of chlorophyll fluorescence (Ayyaz et al., 2020).

Light Response curve data displayed that $Y(I), \operatorname{ETR}(I), Y(I I)$, $\operatorname{ETR}(I I)$, and $Y(N A)$ increased (Figure:2, 5) in control plants and these parameters decreased in plants which were treated with salt $(200,400 \mathrm{mM} \mathrm{NaCl}) . \mathrm{NPQ}, \mathrm{Y}(\mathrm{ND}), \mathrm{Y}(\mathrm{NO})$, $Y(N P Q)$ increased (Table S5, S6) (Figure 3, 5) in both salts stressed $(200,400 \mathrm{mM} \mathrm{NaCl})$ plants and reduced in control plants. While $\mathrm{qP}, \mathrm{qL}$ and $\mathrm{qN}$ increased (Figure 4,6 ) in salt treated plants while decreased in control plants. When the effect of salinity on $M$. oleifera was determined at low light intensity $50 \mu \mathrm{mol} \mathrm{m} \mathrm{m}^{-2} \mathrm{~s}^{-}$it showed that the Quantum yield of photosystem II (PSII) ' $Y$ (II)' was 0.256 in control plants, 0.336 in $200 \mathrm{mM}$ salt stressed plants while it was 0.171 in $400 \mathrm{mM}$ salt stressed plants. Electron transport rate 'ETR(II)' was 6.25 in control plants, 7.16 in plants treated with $200 \mathrm{mM} \mathrm{NaCl}$ and 3.46 in plants given $400 \mathrm{mM}$ salinity. NPQ was 0.265 in control plants, 0.569 in plants given $200 \mathrm{mM}$ salinity while 0.496 in $400 \mathrm{mM} \mathrm{NaCl}$ treated plants. Quantum yield of nonphotochemical quenching by dissipation of energy ' $\mathrm{Y}(\mathrm{NPQ})$ ' was 0.588 in control plants, 0.217 in plants treated with 200 $\mathrm{mM}$ salt and 0.39 in plants providing $400 \mathrm{mM}$ salinity.

Quantum yield of non-photochemical fluorescence quenching by non-dissipation of energy ' $\mathrm{Y}(\mathrm{NO})$ ' was 0.446 in 
control plants, 0.588 in plants treated with $200 \mathrm{mM}$ salt and 0.801 in plants treated with $400 \mathrm{mM} \mathrm{NaCl}$. The assembly of antenna was also reinforced by the light response curves of chlorophyll a fluorescence parameter. By the photoprotective mechanisms ' $q N^{\prime}$ ' inoffensively disperse extra energy as heat. ' $q \mathrm{~L}$ ' is amount of the redox state of the PSII acceptor side (Kramer et al. 2004). At low light intensity $50 \mu \mathrm{mol} \mathrm{m} \mathrm{m}^{-2} \mathrm{~s}^{-1}$ Photochemical quenching of variable chlorophyll fluorescence ' $q \mathrm{P}^{\prime}$ ' in control plants was 0.327 , 0.458 in plants giving $200 \mathrm{mM}$ salinity and 0.505 in plants treated with $400 \mathrm{mM} \mathrm{NaCl}$. ' $\mathrm{qL}$ ' measured in control plants was 0.095 , in plants giving $200 \mathrm{mM} \mathrm{NaCl}$ it was 0.189 and 0.357 in plants treated with $400 \mathrm{mM}$ salt stress. Nonphotochemical quenching of inconstant chlorophyll fluorescence ' $q N^{\prime}$ ' was 0.245 in control plants, 0.388 in plants provided $200 \mathrm{mM}$ salinity and 0.37 in plants treated with 400 $\mathrm{mM} \mathrm{NaCl}$.

At low intensity of light $50 \mu \mathrm{mol} \mathrm{m} \mathrm{m}^{-2} \mathrm{~s}^{-1,}$ quantum yield of PSI ' $Y(I)^{\prime}$ ' was 0.47 in control plants, 0.48 in plants treated with $200 \mathrm{mM}$ while it was 0.29 in plants giving $400 \mathrm{mM}$ salt stress. Electron Transport rate (I) 'ETR(I)' was measured as 12.1 in both control plants and the plants given $200 \mathrm{mM}$ $\mathrm{NaCl}$ and it was 9.6 in plants treated with $400 \mathrm{mM}$ salinity. Quantum yield of non-photochemical energy emission in reaction centers, incomplete by deficiency of electron acceptors ' $Y(N A)$ ' measured as 0.544 in control plants, 0.393 in plants treated with $200 \mathrm{mM} \mathrm{NaCl}$ and 0.052 in plants given $400 \mathrm{mM}$ salt stress.

Quantum yield of non-photochemical energy emission in reaction centers, incomplete by electrons donor deficiency ' $Y(N D)$ ' was 0.011 in control plants, 0.757 in plants given 200 $\mathrm{mM}$ salinity and 0.408 in plants treated with $400 \mathrm{mM}$ salt stress. So, it was noticed that there were little effects on photosynthesis at low salinity level $(200 \mathrm{mM} \mathrm{NaCl})$ as compared to high salt stress ( $400 \mathrm{mM} \mathrm{NaCl}$ ) (Table 5)

Increase in qP due to salinity and is significant effect at level 0.01. $Y(I), Y(I I), Y(N P Q), q L, q N$ are significant at level 0.05 . $\mathrm{ETR}(\mathrm{II}), N P Q, Y(N O), Y(N A), Y(N D)$ are significant at level 0.001 while $\operatorname{ETR}(I)$ is non-significant (ns) (Table 6).

\section{Discussion}

The quantum yield $\left(F_{\mathrm{v}} / F_{\mathrm{m}}\right)$ regulates the PSII efficiency and under adverse ecological state, it predicts the development of plant (Ruban et al. 2015). The results showed that quantum yield decreased as the salinity level increases, whereas in control plants the quantum yield was the maximum. Salinity decreases $\left(F_{\mathrm{v}} / F_{\mathrm{m}}\right)$ which cause photoinhibition and it may cause photodamage. Decrease in $\left(F_{\mathrm{v}} / F_{\mathrm{m}}\right)$ and increase in $F_{\mathrm{o}}$ are beneficial for the light induced decrease in the photosystem efficiency (Maxwell et al. 2000). Hence, it was proved by this experiment that by increasing salinity, Fo also increased in Moringa plants. As decrease in $F_{\mathrm{v}} / F_{\mathrm{m}}$ cause decrease in photosystem II (PSII) quantum yield and it also exaggerated in plants with were provided salt (Maxwell et al. 2000). When the Moringa plants were treated with salt then a lot of fluctuations noticed in chlorophyll $a$ fluorescence, which include the decrease in $F_{\mathrm{v}} / F_{\mathrm{o}}, \mathrm{ET} \mathrm{T}_{\mathrm{o}} / \mathrm{RC}$ while $V_{\mathrm{j}}, V_{\mathrm{l}}$ and $M_{\mathrm{o}}$ increased. As similar parameters were used for the results of maximum values and should be understood by attentions as they depend upon each other and they also have correlations. This behavior of decreased $F_{\mathrm{v}} / F_{\mathrm{o}}$ also noticed under water- stressed situations in primeval and progressive plant species and it cause the disturbances in photosynthesis in PSII (Sudhir et al. 2005). During OJIP there was increase from $O$ to $P$. By the oxidation of $\left(Q_{A}\right)$ at $O$-phase fluorescence was smallest (Strasser et al. 2004), when $Q_{A}$ was reduced at $P$ phase it showed the fluorescence yields (Chen et al. 2009). The background of two intermediates such as ( $\mathrm{J}$ and I) phases are not well categorized (Boisvert et al. 2006), but there were indications that they are connected with the $Q_{A}$ in reduction state and also related with plastoquinone (Strasser et al. 2004). Researches also showed that there is substantial increase in reaction centers of PSII at $\mathrm{J}$ and I phase which designated by $V_{\mathrm{j}}$ and $V_{\mathrm{i}}$ in plants due to ecological strain (Chen et al. 2009), similar comebacks were observed in Moringa plants treated with salinity (Jiang et al. 2008).

The primary fluorescence gradient showed the net rate of shutting the reaction centers of PSII (Qiu et al. 2004) and reoxidized the rate of $Q_{A}$ which showed the variation in plants by increasing ecological strain (Chen et al. 2009). As Moringa plants were treated with different salinity levels, it was observed that the photosystem II (PSII) efficiency and reoxidation rate of $Q_{A}$ decreased and these variations were best observed at $400 \mathrm{mM} \mathrm{NaCl}$ (Chen et al. 2009). Performance index $\left(\mathrm{PI}_{\mathrm{ABS}}\right)$, decreased by the elevation in physical stress (Živčák et al. 2008).

There are three efficient components of Performance index $\left(\mathrm{PI}_{\mathrm{ABS}}\right)$ which are light energy absorption, trapping of energy and energy change into electron transport. It was observed that Performance index absorbance $\left(\mathrm{PI}_{\mathrm{ABS}}\right)$ changed by the two salinity levels. It was also noticed that the performance index absorbance $\left(\mathrm{PI}_{\mathrm{ABS}}\right)$ decreased by the different salinity levels (0 to $400 \mathrm{mM} \mathrm{NaCl}$ ). In this study it was noticed that there is a great difference in $\mathrm{PI}_{\mathrm{ABS}}$ in control plants and the plants which were treated with $400 \mathrm{mM} \mathrm{NaCl}$. Our results are matched with the other studies which also indicated the great differences in $\mathrm{PI}_{\mathrm{ABS}}$ in following salt treated plants (e.g., Triticum aestivum and Acer spp.). The results showed that the $T$. aestivum are salt stressed (Mehta et al. 2010), the variations in $\mathrm{Pl}_{\mathrm{ABS}}$ were high in salt treated Moringa plants in which efficiency of photosystem II (PSII) declined.

The potential quantum yield of PS(II) is demonstrated by $\mathrm{Fv} / \mathrm{Fm}$ (Lichtenthaler and Babani et al. 2004). AT Fv/Fm, in the donor side of photosystem II (PSII) the thylakoid assembly is harmed (Skórzyńska-Polit and Baszyński et al. 1997). The reduction in Fv/Fm was due to the reduction in Fm that is distinctive to photoinhibition (Ruban et al. 2016). $\mathrm{Fm}$ increased by the destruction in the reaction centers of PSII (Krause et al. 1991).

In current study it was cleared that the reduction in Fv/Fm, decrease the rate of electron transport (ETRII) of PSII by salinity. In barley it was observed that the Fv/Fm remained unchanged by salinity but the value of ETRII was decreased (Baker et al. 2008). The sunlight absorbed by the chlorophyll molecules may be used in photosynthesis or discharge as heat energy (Macedo et al. 2008) or it may reemit like lightchlorophyll a fluorescence which is notorious as nonphotochemical quenching (Krause and Weis et al. 1991). NPQ and $\mathrm{qN}$ these two parameters are related with energy discharge to protect PSII.

The factor of NPQ which decrease the regulation of PSII antenna competence caused by increase $\left[\mathrm{H}^{+}\right]$in lumen, and this increased proton gradient cause the reduction in PSI and 


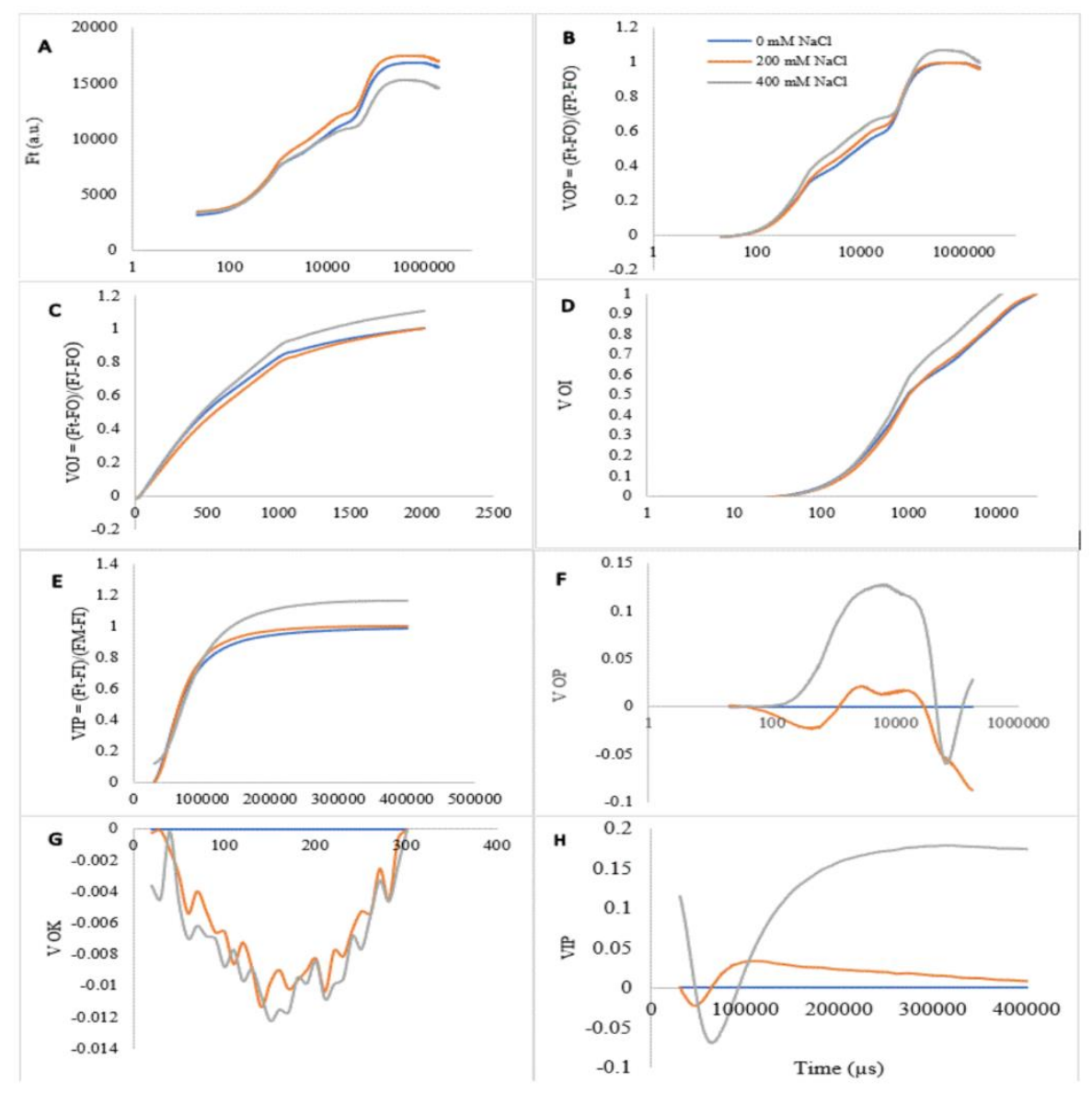

Fig 1. (A) Ft (a.u.), (B) VOP = (Ft-Fo)/(FP-Fo), (C) VOJ = (Ft-Fo)/(FJ-Fo), (D) $\bigvee_{\mathrm{OI}}(\mathrm{E}) \mathrm{V}_{\mathrm{IP}}=(\mathrm{Ft}-\mathrm{FI}) /(\mathrm{FM}-\mathrm{FI}),(\mathrm{F}) \mathrm{Vop}(\mathrm{G}) \mathrm{V}_{\mathrm{OK}}(\mathrm{H}) \mathrm{V}_{\mathrm{PP}}$ from OJIP the Moringa oleifera when four week old plants were subjected to different salinity levels $(0,200$ and $400 \mathrm{mM}$.).

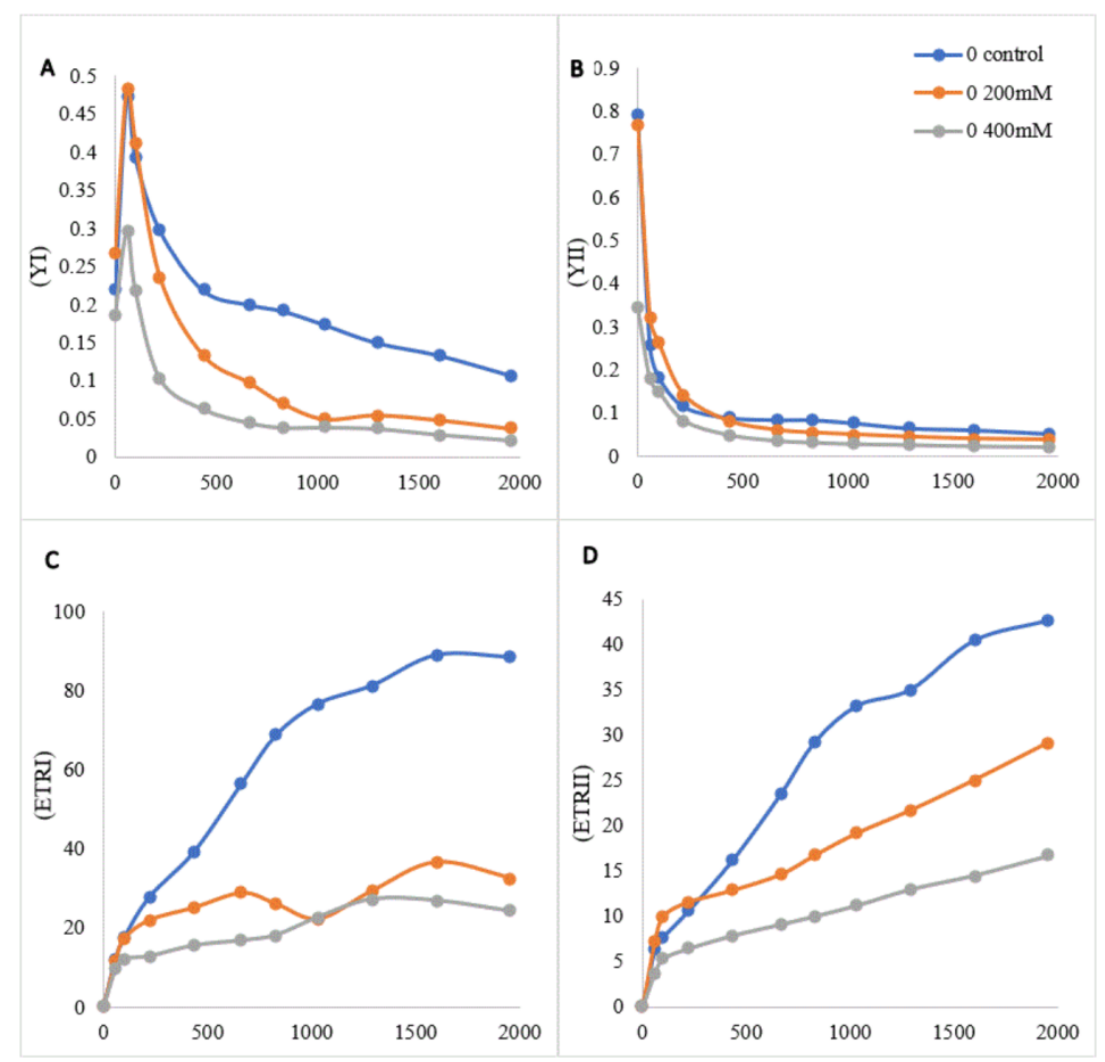

Fig 2. A general legend. (A) Y(I), (B) Y(II), (C) ETR(I), (D) ETR(II) from light curve of Moringa oleifera when four-week-old plants were subjected to salt stress $(0,200,400 \mathrm{mM}) \mathrm{NaCl}$ for three weeks. 

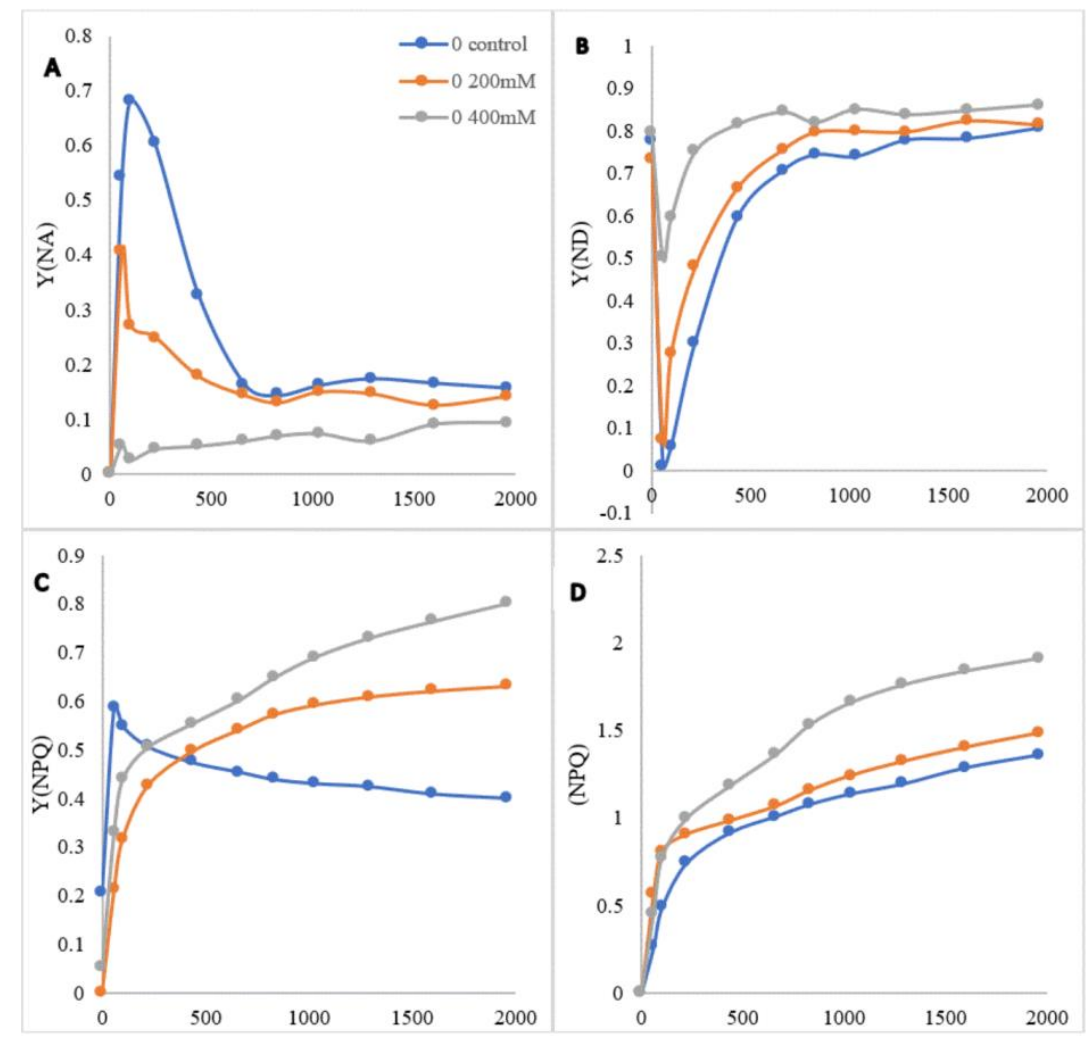

Fig 3. (A) $Y(N A)$, (B) $Y(N D), Y(N P Q)$, (D) NPQ from light curve of Moringa oleifera when four-week-old plants were subjected to salt stress $(0,200,400$ $\mathrm{mM}) \mathrm{NaCl}$ for three weeks.

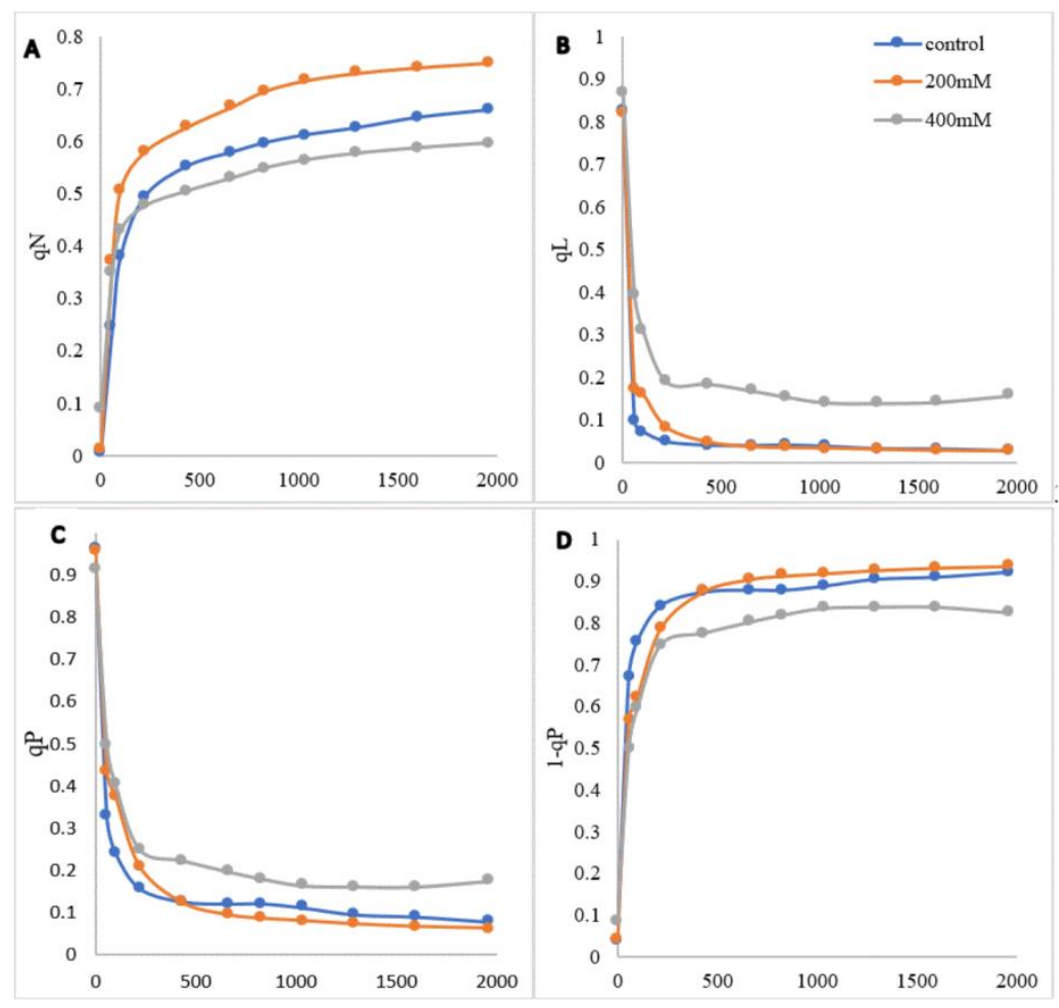

Fig 4. (A) qN, (B) qL, (C) qP, (D) 1-qP from light curve of Moringa oleifera when four-week-old plants were subjected to salt stress $(0,200,400 \mathrm{mM})$ $\mathrm{NaCl}$ for three weeks. 


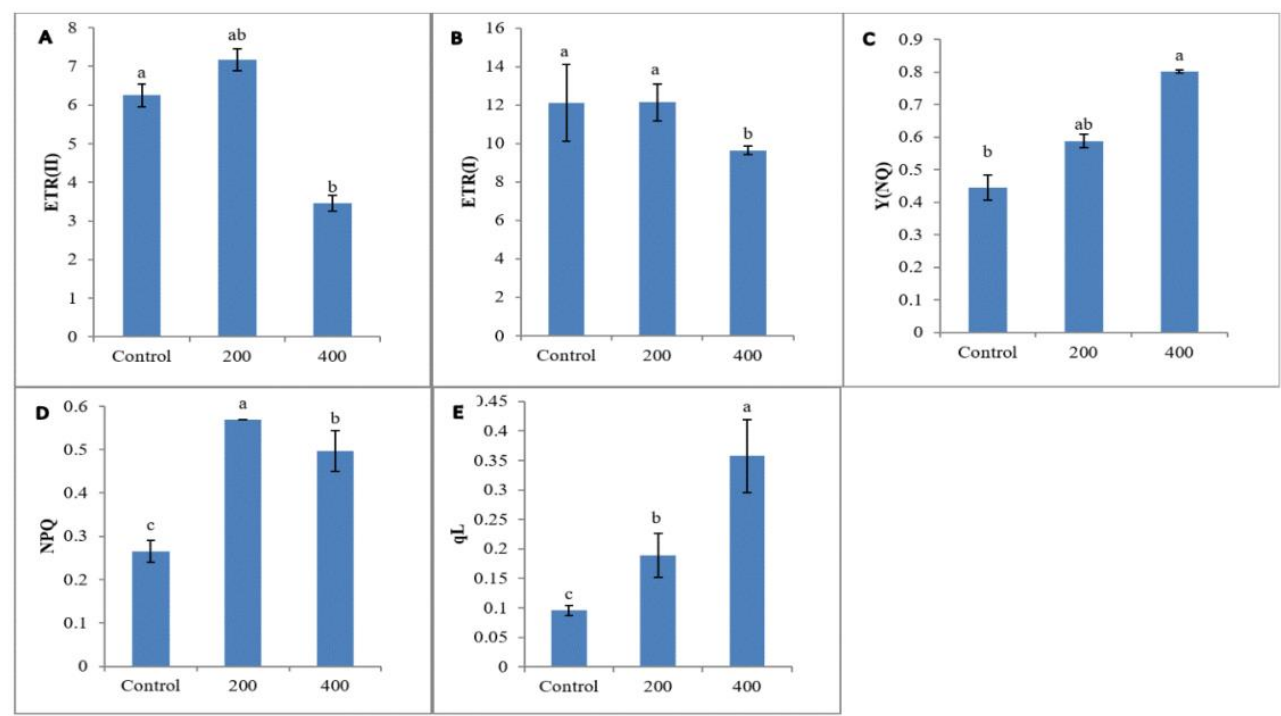

Fig 5. (A) ETR(II), (B) ETR(I), (C) Y(NQ), (D) NPQ, (E) qL from light curve of Moringa oleifera when four-week-old plants were subjected to salt stress $(0,200,400 \mathrm{mM}) \mathrm{NaCl}$ for three weeks.

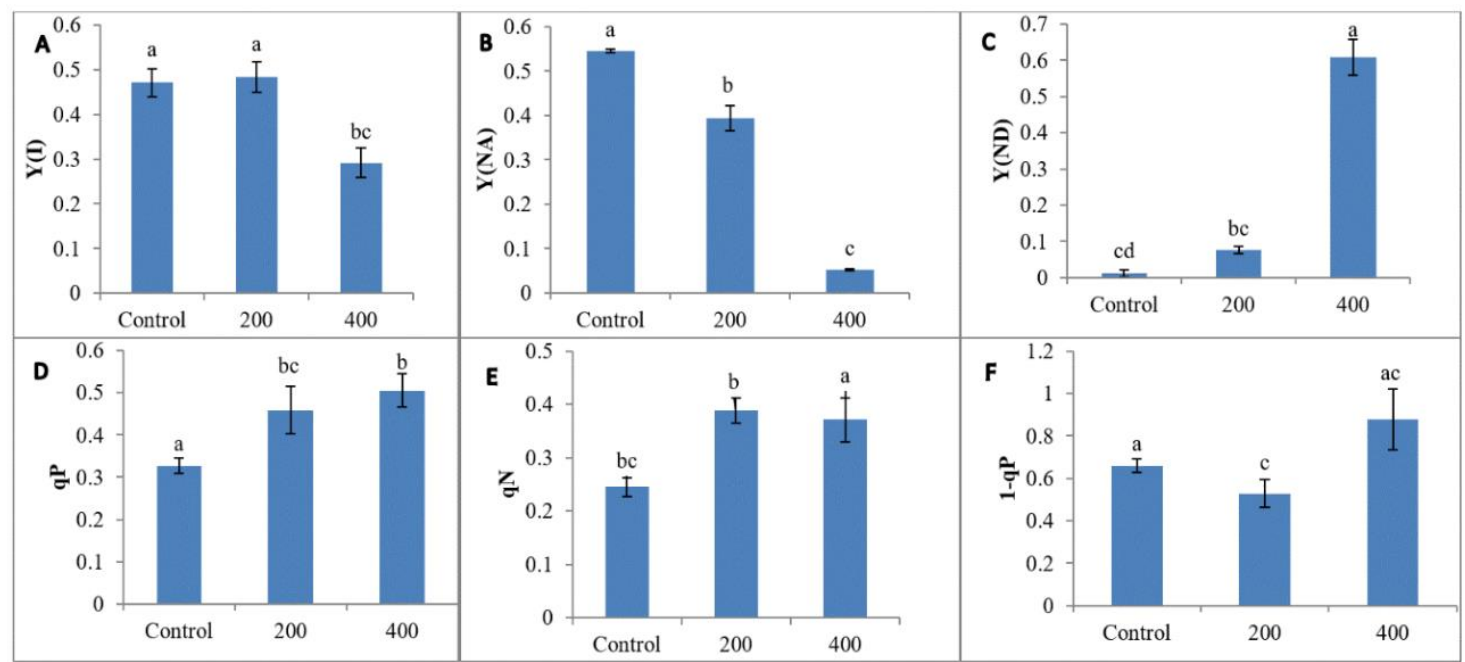

Fig 6. (A) $Y(I)$, (B) $Y(N A)$, (C) $Y(N D)$, (D) qP, (E) qN, (F) 1-qP from light curve of Moringa oleifera when four-week-old plants were subjected to salt stress $(0,200,400 \mathrm{mM} \mathrm{NaCl})$ for three weeks.

PSII oxidoreduction condition (Ruban et al. 2016). Our data showed that the NPQ and $q N$ increased by salt stress in Moringa. qL increased in salt treated plants.

The photoinhibition of PSII is related with the open and closed reaction centers of photosystem II (PSII) (Ruban et al. 2015). The current study showed that the $\mathrm{qP}$ increased in salt stressed plants. $Y(I)$ is the quantum yield of PSI and is measured by the significant amount of non-photochemical energy discharge (Y(NA) and Y(ND) (Schreiber et al. 2017). Our data revealed that $Y(I)$ and $Y(N A)$ in Moringa declined by salinity but $Y(N D)$ is enlarged. It also showed that the lower $Y(I)$ cause the decrease in the electron transport rate (ETRI) of PSI due to salt stress. However, further researches should be done all over the world to know the effects of salinity on M. oleifera.

\section{Materials and Methods}

Experiment was conducted in Botanical Garden and arranged in completely randomized design comprising 3 replications with three salt levels (i.e. 0, 200, $400 \mathrm{mM} \mathrm{NaCl}$ ). After washing, seeds were sown in pots, filled with sand. After growth of seedlings for four weeks, salt stress was given in full strength Hoagland nutrient solution. The treatment was repeated after a week. After 21 days of salt stress, OJIP and light curve calculations was done.

\section{Light response curves analysis}

Saturation pulse is used to predict light response curve (LC) for calculating the photosynthetic productivity of PSI and PSII. In the presence of actinic light, nominal and extreme chlorophyll fluorescence (Fo and Fm correspondingly) was calculated. Highest productivity of photosystem II (Fv/Fm) was determined by (Fm-Fo)/Fm. PAR (photosynthetically Active Radiation $=P A R$ ) was raised from 0, 58, 100, 221, 435, $665,830,1033,1292,1599,1957 \mu_{m o l m}^{-2} \mathrm{~s}^{-1}$ for 5 minutes at $20 \mathrm{sec}$ pauses by using red actinic light at regular intervals. In the presence of actinic light at $40 \mathrm{sec}$ pauses, saturation pulse $\left(8,000 \mu \mathrm{molm}^{-2} \mathrm{~s}^{-}\right.$intensity, $800 \mathrm{~ms}$ width) was provided for 5 minutes at $20 \mathrm{sec}$ pauses. Next by 
increasing light, Fs was determined and $\mathrm{Fm}^{\prime}$ and $\mathrm{Pm}^{\prime}$ were measured later for separate saturation pulse. DUAL PAM100 Software was used to get Rapid light curve and photosynthetically active radiation was provided via constructed in red light discharging diodes (Table 2).

\section{Fast Chlorophyll a Transient (OJIP Test)}

Moringa plants were placed in dark and leaves were subjected to continuous light pulse $\left(3500 \mu \mathrm{molm}^{-2} \mathrm{~s}^{-1}\right)$ where the parameters of chlorophyll a fluorescence were determined. Then data was analyzed in excel (Table 1).

\section{Statistical analysis}

Statistical analysis of the data was subjected to a One Way Completely Randomized Analysis of Variance (1WCR ANOVA) by using a COSTAT software (Cohort Software, Berkeley, California).

\section{Conclusion}

This study showed the salinity effects on $M$. oleifera could be determined by the OJIP and light response curve. Quantum yield $\left(F_{\mathrm{v}} / F_{\mathrm{m}}\right.$ and $\left.F_{\mathrm{v}} / F_{\mathrm{o}}\right)$, photosystem II performance $\left(\mathrm{Pl}_{\mathrm{ABS}}\right)$ and electron flux per reaction center $\left(E T_{0} / R C\right.$ ) decreased with increasing salt stress from $0 \mathrm{mM}$ to $400 \mathrm{mM}$ which reduced the development in parts of the Moringa plant. Disturbance of photosynthetic rate in Moringa plants treated with salt showed that Moringa can withstand low salinity levels $(200 \mathrm{mM} \mathrm{NaCl})$ with a small decrease in photosynthesis.

\section{Acknowledgment}

All authors are thankful to Dr. Muhammad Ahsan Farooq and Mr. Asim Bilal for their moral support and guidance in this study.

\section{References}

Ayyaz A, Amir M, Umer S, Iqbal M, Bano H, Gul HS, Noor Y, Javed M, Athar HR, Zafar ZU, Farooq MA (2020) Melatonin induced changes in photosynthetic efficiency as probed by OJIP associated with improved chromium stress tolerance in canola (Brassica napus L.). Heliyon. 6(7).

Baker NR (2008) Chlorophyll fluorescence: A probe of photosynthesis in vivo. Annu Rev Plant Biol. 59: 89-113.

Bussotti F (2010) The JIP test: a tool to screen the capacity of plant adaptation to climate change. Scand J For Res. 25: 43-50.

Jama B, Nair PKR, Kurira PW (1989) Comparative growth performance of some multipurpose trees and shrubs grown at Machakos, Kenya. Agrofor Syst. 9(1): 17-27.

Kalaji H M (2011) Effects of salt stress on photosystem II efficiency and $\mathrm{CO}_{2}$ assimilation of two Syrian barley landraces. Environ Exp Bot. 73: 64-72.

Kalaji M H, Pietkiewicz S (1993) Salinity effects on plant growth and other physiological processes. Acta Physiol Plant. 15(2).

Khalid A (2015) Photosynthetic capacity of canola (Brassica napus L.) plants as affected by glycinebetaine under salt stress. J Appl Bot Food Qual. 88: 78-86.

Leone A (2015) Cultivation, genetic, ethnopharmacology, phytochemistry and pharmacology of Moringa oleifera leaves: an overview. Int J Mol Sci. 16(6): 12791-12835.
Munns R, Tester M (2008) Mechanisms of Salinity Tolerance. Annu Rev Plant Biol. 59(1): 651-681.

Schreiber U, Klughammer C (2008) New accessory for the Dual-PAM-100: the P515/535 module and examples of its application. PAM Application Notes 1: 1-10.

Boisvert S, David J, Robert C (2006) Quantitative analysis of the experimental O-J-I-P chlorophyll fluorescence induction kinetics. FEBS Journal 273(20): 4770-4777.

Chen L S, Cheng L (2009) Photosystem 2 is more tolerant to high temperature in apple (Malus domestica Borkh.) leaves than in fruit peel. Photosynthetica 47(1): 112-120.

Jiang $H$ (2008) Aluminum-induced effects on Photosystem II photochemistry in Citrus leaves assessed by the chlorophyll a fluorescence transient. Tree Physiol. 28(12): 1863-1871.

Kramer DM (2004) New fluorescence parameters for the determination of $Q \mathrm{~A}$ redox state and excitation energy fluxes. Photosynth Res. 79(2): 209-209.

Krause GH, Weis E (1991) Chlorophyll Fluorescence and Photosynthesis: The Basics. Annu Rev Plant Physiol Plant Mol Biol. 42(1): 313-349.

Lichtenthaler HK, Babani F (2004) Light Adaptation and Senescence of the Photosynthetic Apparatus. Changes in Pigment Composition, Chlorophyll Fluorescence Parameters and Photosynthetic Activity. In: Papageorgiou G.C., Govindjee (eds) Chlorophyll a Fluorescence. Advances in Photosynthesis and Respiration, vol 19. Springer, Dordrecht.

Macedo R (2008) Effects of the herbicide bentazon on growth and photosystem II maximum quantum yield of the marine diatom Skeletonema costatum. Toxicol In Vitro 22(3): 716-722.

Maxwell K, Johnson GN (2000) Chlorophyll fluorescence-a practical guide. J Exp Bot 51(345): 659-668.

Mehta, P (2010) Chlorophyll a fluorescence study revealing effects of high salt stress on Photosystem II in wheat leaves. Plant Physiol Biochem. 48(1): 16-20.

Qiu B (2004) Effects of potassium on the photosynthetic recovery of the terrestrial cyanobacterium, nostoc flagelliforme (cyanophyceae) during rehydration. J Phycol. 40(2): 323-332.

Ruban AV (2015) Evolution under the sun: optimizing light harvesting in photosynthesis. J Exp Bot 66(1): 7-23.

Schreiber U (2017) Redox changes of ferredoxin, P700, and plastocyanin measured simultaneously in intact leaves. Photosynth Res.134 (3):343-360.

Skórzyn-ska-Polit E, Baszyn-ski T (1997) Differences in Sensitivity of the Photosynthetic Apparatus in Cd-Stressed Runner Bean Plants in Relation to Their Age. Plant Sci. vol. 128: 11-21.

Strasser RJ, Tsimilli-Michael M, Srivastava A (2004) Chlorophyll a fluorescence: a signature of photosynthesis. Advances in photosynthesis and respiration series.19: 321362.

Sudhir PR (2005) The effects of salt stress on photosynthetic electron transport and thylakoid membrane proteins in the cyanobacterium Spirulina platensis. BMB Reports. 38(4): 481-485.

Živ̌cák M (2008) Performance index as a sensitive indicator of water stress in Triticum aestivum L. Plant Soil Environ. 54:133-139. 